\title{
Tradução, Paródia e paráfrase: as reescrituras poéticas de Manuel Bandeira
}

\author{
Célia Luiza Andrade Prado*
}

Bandeira é um refazedor da tradição. Um leitor dos clássicos e um reescrevedor de poesia.

Affonso Romano de Sant'Anna

\begin{abstract}
A broader approach to translation considers it as a form of rewriting. This manipulative process overlaps with the concept of adaptation. If on one hand rewriting can be seen as an act of expropriation, on the other, it frees it from the source text straightjacket and disrupts the concept of work of art as a unique and irreplaceable object. Many types of textual transference, - paraphrase, parody and "translation into modern" - by Manuel Bandeira are characterized by the manner how they are freely recreated in the target language and are highly praised by the critics. The objective of this paper is not to make a detailed contrastive analysis of the poems recreated by Bandeira, but to provide some illustrative examples of the discussion about adaptation/ translation concepts.
\end{abstract}

Keywords: Translation - Rewriting - Paraphrase - Parody.

Resumo: A maneira abrangente de repensar a tradução como uma forma de reescritura aproxima-a da adaptação e evidencia o seu caráter autoral. Se por um lado a reescritura é considerada uma atividade usurpadora, por outro liberta a obra do jugo do texto fonte, modificando o conceito da obra de arte como objeto único e insubstituível. Os vários tipos de transposição textual - paráfrase, paródia e "tradução para o moderno" - de Manuel Bandeira se caracterizam pela liberdade como são recriadas na língua alvo e altamente consideradas pela crítica. 0 objetivo deste trabalho não é de elaborar uma análise metódica e detalhada dos poemas recriados por Bandeira, mas de apresentar alguns exemplos que se inserem na discussão sobre conceitos de adaptação e tradução.

Palavras-chave: Tradução - Reescritura - Paráfrase - Paródia.

\footnotetext{
* Mestre e doutoranda em Estudos Linguísticos e Literários em Inglês FFLCH-USP. Email: celprado@uol.com.br.
} 


\section{Introdução}

Quando se trata de tradução poética, a ideia consensual é de que poesia é intraduzível, pois o tradutor está sujeito a grandes restrições impostas não só pela língua, mas também pelo gênero. A ideia de "destruição" da obra de arte poética no processo tradutório está pari passu com a concepção romântica que sacraliza a obra de arte como objeto único e insubstituível.

Walter Benjamin, em A obra de arte na época de sua reprodutibilidade técnica (1936), aponta três aspectos que mistificam a obra de arte: aura, valor cultural e autenticidade. Segundo Benjamin, a originalidade é posta em xeque pelas novas possibilidades artísticas decorrente da reprodução técnica, levando a repensar os conceitos de originalidade. Subjacente a essa reflexão acha-se também a questão da autoria do texto original na relação com a tradução, argumentando que a tradução, apesar de ser um ato reprodutivo, não é menos criativa que a produção do texto primeiro. Benjamin, em A tarefa do tradutor, coloca o valor do texto traduzido e do texto fonte em pé de igualdade, ao afirmar que o original se prolonga nas traduções e por elas são ampliadas e renovadas.

Também Lawrence VenUTI (2002: 65) atenta para essa visão romântica quando observa que: "enquanto a autoria é comumente definida como originalidade, a tradução é derivada, nem autoexpressão nem única: ela imita outro texto". Essa percepção será revista por Derrida, (apud CAMPOS 1985) questionando a percepção de inautenticidade da tradução, que, na dimensão desconstrutivista, retoma o pensamento de Benjamin. Derrida observa que a tradução confere "sobrevida" ao texto por meio da transformação do original e não de sua reprodução, abolindo a questão da anterioridade e da sacralização do texto de origem.

Por ser a poesia considerada, ainda conforme a visão romântica, uma obra unívoca fruto de inspiração, cuja "aura" e valor cultural são 
irreproduzíveis, o ato tradutório seria, por natureza, menos criativo e "original". Contudo, os próprios fatores condicionantes do texto fonte fornecem subsídios à recriação do poema em outra língua. Para Haroldo de CAMPOS (2004: 35), quanto mais intraduzível parece um texto, mais recriável será, porque "numa tradução dessa natureza não se traduz apenas 0 significado, traduz-se o próprio signo, ou seja, sua fisicalidade, sua materialidade mesma".

Assim, a tradução, antes considerada por muitos como uma atividade menor, inferior, usurpadora, é, numa visão pós-moderna, vista como um ato de reescritura de caráter autoral que a liberta do jugo do texto fonte. A reescritura, que parte do pressuposto de que qualquer texto assimila, empresta, imita e reescreve outro, e de que um texto está sujeito a diversas interpretações, é o avesso da tradução literal, pois não pretende reproduzir, mas produzir algo diferente: a tradução é um ato de recriação.

Hoje o conceito de reescritura e recriação estaria subjacente à metáfora da refração, emprestada da ótica por André LefEVERE (1992: 9), que explica como uma obra passa a ser consumida e conhecida em outra cultura, desempenhando um papel importante na evolução dos sistemas literários. A tradução, o tipo mais flagrante de refração, e potencialmente o mais influente na projeção de representação de autor e obra, levando-os para além dos limites da cultura geradora, pode torna-se o original para a maioria das pessoas que não tem acesso à obra que a originou (idem 2003: 235). Além da tradução, a adaptação, a paráfrase, a paródia, a estilização e a apropriação são refrações e modos de reescrituras; todavia, não há um consenso com relação à conceituação teórica dessas transposições textuais, que depende muito de fatores temporais, espaciais e sociais. No entanto, faz-se necessário estabelecer critérios para efeito de análise dos poemas de Bandeira aqui apresentados. Para tal, recorreremos às teorizações de Affonso de Romano SANT'ANNA (1985) sobre paródia, paráfrase e apropriação como modelo na análise de tais obras. 


\section{Bandeira tradutor}

Manuel Bandeira foi um tradutor profícuo, um recriador à altura do poeta. Mas se, por um lado, suas traduções "não constituem, em si mesmas, um corpus definidor de programa" (WANDeRLeY 1988: 8) e o legado de suas traduções em prosa nos leva a presumir que Bandeira tenha enveredado pelos caminhos da tradução por motivos financeiros, ou como ele próprio define, "por dever do ofício", por outro, na tradução de poesia como recriador, o poeta também se sobressai.

WANDERLEY (1988: 2) observa que a história da tradução no Brasil na primeira metade do século XX, período em que Bandeira atuou ativamente nessa área, é marcada "por algum espontaneísmo, a experiência de amador, 0 caráter dominical", apesar da seriedade que muitos imprimiram à tarefa. Nesse período, não houve movimento de caráter programático e as teorizações a respeito do trabalho de tradutor não passam de reflexões sobre a experiência em nível pessoal. Desses tradutores, incluindo Bandeira, o que se encontra são depoimentos em que o poeta reflete sobre a atividade partindo da sua práxis.

Não se pode afirmar que Bandeira tenha desenvolvido uma teoria de tradução. 0 que se encontra são depoimentos nos quais o poeta reflete sobre a atividade partindo da sua práxis, levantando questões, como a intraduzibilidade da poesia e a busca por equivalência. A afirmação de Bandeira, "só no chão da poesia piso com alguma segurança" (BANDElRA 1966: 109), revela a congenialidade entre o poeta e o tradutor de poesia. 0 texto fonte se amálgama com a o espírito criador "que resulta de um jogo de intuições".

Pelo fato de Bandeira ter sido primordialmente poeta, a tradução de poesia ocupa um lugar central não só nos estudos críticos sobre suas traduções como na sua própria reflexão sobre o processo tradutório. A longa e íntima convivência "com o melhor do que Ihe poderia dar a literatura de todos os 
tempos e países" forjou o "tradutor de várias línguas, mestre de cultura hispano-americana" (Bosı 2004: 365). 0 trabalho de Bandeira como tradutor se inicia quando havia passado a fase modernista mais revolucionária, fazendo, sugerindo que não se deve aplicar nenhum rótulo caracterizador a essa sua atividade.

\section{Reescrevendo poemas}

A primeira coletânea poética de traduções de Manuel Bandeira, da qual se tem registro, só aparece em 1945. Na poesia, Bandeira parece escolher 0 que quer traduzir, pois, como ele atesta: "só traduzo bem os poemas que gostaria de ter feito, isto é, os que exprimem coisas que já estavam em mim, mas informuladas" e essas traduções se deram "por necessidade de expressão própria" (BANDEIRA 1966: 125). Assim, Bandeira apropria-se do texto fonte e faz seu o que é de outro.

Abgar Renault, contemporâneo de Bandeira, analisa a tradução de alguns sonetos de Elizabeth Barrett Browning e um poema de Christina Georgina Rossetti, concluindo que Bandeira recria o original:

São páginas mais consideráveis de Manuel Bandeira as traduções de alguns poemas ingleses, que podem ser incorporados à sua obra como produção própria, sem embargo da fidelidade original, tal a assimilação e absorção dos textos estrangeiros, da sua forma, da sua técnica e do seu espírito à forma, à técnica, ao espírito do tradutor (RENAULT 1986: 25).

Renault não poupa elogios às traduções de Bandeira, cujo êxito adviria não só do conhecimento das nuances da língua fonte como da "proximidade de algumas características de sua poética com as da poética inglesa" (Ibid.), que seriam: o sentido de economia, a condensação e a carga emocional sem sentimentalismo. Bandeira reage a todo esse enaltecimento, considerando-o um exagero: "Gostaria que fosse verdade o louvor tão lisonjeiro de meu 
querido amigo Abgar. Mas devo confessar que sou bastante fundo no inglês. Fundo no sentido que a palavra tem na gíria" (BANDEIRA 1966: 123). As traduções, todavia, sempre reeditadas, provam que Bandeira não estava com a razão.

Stefan BAcIú (1966: 86) também concorda que as traduções de Bandeira são recriações, nas quais se revelam o "bom gosto, atenção para os menores detalhes, vestindo a obra de um aspecto digno, talvez inexistente no original", mesmo quando se trata de literatura de massa, best sellers, escolhidos pelos editores, como por exemplo, Tarzan. Mas é em Poemas traduzidos que as qualidades elencadas por Baciú se exacerbam: "não se deve atentar tão-somente para a seleção das peças, que demonstra uma vez mais 0 excepcional bom gosto de Bandeira, mas para o amor dedicado à arte de traduzir" (ibid.).

Esse autor ainda ressalta a importância de Bandeira na divulgação de poetas desconhecidos do público por meio de antologias e traduções, os quais também vieram a influenciar a literatura moderna: "No mundo da poesia, Bandeira sempre andou nas regiões mais profundas, no que se refere à técnica de traduzir e, na vanguarda da vanguarda, para descobrir poetas novos e poetas importantes desconhecidos no Brasil" (ibid.).

Sérgio Milliet é outro crítico que destaca a habilidade de Bandeira em recriar o poema em português, num processo quase autônomo de autoria. A propósito da tradução de um poema de Cristina Rossetti, afirma:

\footnotetext{
Se se colocar em frente desse texto o original inglês ter-se-á uma idéia precisa daquilo que eu insisto em denominar equivalência e que consiste não na tradução exata das palavras, mas na expressão do mesmo sentimento, e até das mesmas imagens, sob forma diferente (MILLIET apud BANDEIRA 1996: 123).
}

Tal definição de equivalência, que Bandeira sempre procurou na suas traduções, embasa o princípio de tradução como recriação e se confirma nas próprias palavras do poeta tradutor: "A tradução de um poema é, afinal de contas, uma recriação. Assim que ela só é total e perfeita quando sai fiel ao 
poeta traduzido e fiel ao poeta tradutor" (BANDEIRA 1978: 229). Para MILTON (1993: 170), as traduções de Bandeira "são distintivas por seu frequente distanciamento do texto-fonte, dando uma impressão geral deste em vez de uma tradução palavra por palavra".

WANDERLEY (1988: 11-12) identifica alguns aspectos na poética de tradução de Bandeira: 1) a busca por equivalência na expressão do sentimento e das imagens. Bandeira "elege seu texto com base em ressonâncias pessoais"; 2) a ideia dos versos intraduzíveis quando "a emoção poética está rigorosamente condicionada às palavras" (BANDEIRA 1966: 123), concluindo que para o poeta haveria graus de traduzibilidade; e 3) a asserção de Bandeira de que era "bastante fundo em inglês", que evidencia uma teoria à frente de seu tempo, subentendo-se que não é indispensável um conhecimento profundo da língua de partida, mas sim da de chegada. O alegado desconhecimento do inglês e a ausência de uma teoria explícita sobre tradução levam Wanderley a concluir que "há em MB uma teoria da tradução toda feita de instintos", reproduzindo a afirmação de BANDEIRA (1958: 100): "Os meus achados, em traduções como em originais, resultam sempre de intuições".

Os poemas traduzidos por Bandeira, segundo WANDERLEY (1988, passim), apresentam um "vezo bandeiriano", fruto de "solução mais pessoal que fiel" ao adicionar elementos que não constam do original, conseguindo muitas vezes "tornar melhor que o original". Tais enxertias consistem de marcas típicas da poesia de Bandeira: musicalidade, inversões, toque de arcaísmo, palavras recorrentes de seu próprio vocabulário, seu próprio universo imagístico. Seria uma outra maneira de dizer que as traduções de Bandeira são recriações com características autorais, como aponta Vanete Dutra Santana sobre a relação tradutor/ autor:

Considerar o texto de partida superior, neste contexto, não faria sentido, tratando-se, antes, da afirmação de um pré-conceito que se impõe a despeito do reconhecimento de que a diferença é inerente à tradução e a despeito da percepção da relatividade do que se tem classificado como original (SANTANA 2008: 293). 
À ideia de Bandeira de que há poesia intraduzível, opõe-se o resultado, sempre valorizado, de suas traduções e a afirmação de que há poemas traduzíveis e intraduzíveis, "mas que o poeta-tradutor pode achar em outra língua a mesma virtude musical em outra combinação de palavras" (BANDEIRA 1978: 293). Essa concepção nos remete aos conceitos de Haroldo de CAMPOS (2004: 32) de que tradução é a reconfiguração da informação estética, que transcende a semântica, no que concerne à "imprevisibilidade, à surpresa, à improbabilidade da ordenação de signos".

Bandeira resolve o impasse da impossibilidade e ao mesmo tempo a necessidade da tradução numa postura pós-moderna avant la lettre, que nos faz pensar na transcriação haroldiana e na aporia derrideana. Mais que traduzir, Bandeira recria: "a criação de um símile do poema original capaz de produzir, nos leitores da língua alvo, efeitos semelhantes aos produzidos pelo dito poema nos leitores da língua fonte" (PAES 1990: 61). Tanto assim, que algumas de suas traduções foram publicadas entre versos de sua autoria e passariam por uma criação original, como a "Paráfrase de Ronsard", em Cinza das horas, dois poemas de Rossetti, em Estrela da manhã, e o de Browning, em Libertinagem, traduções "geralmente reconhecidas como de maior interesse do que os originais" (MILTON 1993: 170).

Dentre os contemporâneos de Bandeira, Mário de Andrade advoga a tradução como transposição criativa, na expressão de Jakobson, fugindo das velhas dicotomias fiel/infiel, original/cópia:

Filosoficamente, nos todos sabemos que poesia é intraduzível, e eu sou daqueles que afirmam que, dentro dela, street ou calle não correspondem à rua. Na verdade os poemas não são traduzíveis; em poesia, há que conceituar a tradução como um processo de substituição. 0 que o tradutor faz é substituir um objeto por outro, apenas observando do primeiro, para efeitos da substituição, 0 elemento funcional (o assunto) e as suas consequências estéticas (a realização técnica). O segredo, na substituição poética, não é tanto preservar 0 assunto, que, exemplificativamente, consistiria apenas em substituir um vaso por um vaso, e não por um abajur. 0 importantíssimo, o definitivo é a substituição das consequências estéticas, porque nelas é que se contêm o estado de sensibilidade em 
que o poeta definiu o assunto, e os elementos de beleza utilizados para nos convencer (ANDRADE. In: Poesia e prosa I, 1958: 569).

Esse pensamento vai ao encontro da opinião de Haroldo de CAMPOS (1977: 109) de que o poeta seria melhor tradutor de poesia, pois "o repertório de linguagem do poeta de ofício (seu estoque de formas, seu domínio das possibilidades de agenciamento estético da língua para a qual o texto é traduzido) é infinitamente superior ao do scholar que faz às vezes de poeta".

Assim como para Campos, o trabalho de tradutor por ser tributário da atividade primeira não é secundário, pois é também criativo, em Bandeira também se observa uma interdependência produtiva entre o fazer poético e 0 traduzir. PAES (1990: 85) observa que, a oficina de tradutor de poesia não difere substancialmente da oficina de poeta e que ambas estariam alicerçadas na "intuição criadora" e na "máquina secreta da subconsciência".

A essas reflexões podemos acrescentar a de Leonardo FróES, que prefaciou o opúsculo Alguns poemas traduzidos (2007: 10): "O poeta traduz, tocado ao ler, para se apropriar do que traz, naquele instante, alguma nota de conhecimento afetivo a seu próprio respeito". Donde se conclui que a congenialidade com a obra desempenha papel primordial na tradução de poesia.

\section{Uma antologia bandeiriana da poesia universal}

O primeiro trabalho de tradução publicado de Manuel Bandeira que se tem registro só aparece na década de 30, com 0 tesouro de Tarzan, pela Companhia Editora Nacional. Em 1945, a editora R. A. reúne diversos poemas, numa antologia com a modesta tiragem de 350 exemplares e várias vezes reeditada. A primeira edição comercial de Poemas Traduzidos é lançada pela Globo, em 1948. Segundo os editores: 
Este livro revela aos amigos da poesia uma parte nova, quase desconhecida, da obra de Bandeira. [...] vemos a arte de Bandeira adaptar-se aos gêneros mais diversos, recriando em nosso idioma algumas jóias da literatura mundial, intraduzíveis se não fosse esse encontro da sensibilidade do artista tradutor com a dos grandes poetas traduzidos. (Poemas traduzidos, 1948. Grifo nosso).

Para BANDEIRA (1966: 107), é difícil organizar qualquer espécie de antologia, pois todas o deixaram insatisfeito e recebeu "críticas nem sempre justas". As poesias reunidas apresentam uma diversidade de estilos, escolas e línguas que comprovam que Bandeira não seguiu nenhum critério canônico ou paideuma. Dentre os mais de cem poetas escolhidos, acham-se românticos, renascentistas, modernos: Goethe, Bashô, Lorca, Heine, Paul Éluard, Dickinson, Soror J uana Inés de La Cruz, Elisabeth Bishop, Borges. BACIú (1966: 90) acredita que embora tenha havido a influência de editores, redatores e amigos na escolha de Poemas traduzidos, a maioria foi selecionada pelo próprio Bandeira tornando-se uma "antologia bandeiriana universal". Ainda com relação à tradução poética, Bandeira traduziu, em 1962, o longo poema provençal Miréia, de Frédéric Mistral, publicado em 1859 e agraciado com o prêmio Nobel de Literatura, e o Rubaiyat, em 1965, de Omar Khayyan, a partir da versão francesa de Franz Toussaint.

As traduções de Bandeira, como já foi dito acima, não se restringem à transposição do texto poético de uma língua para outra. Enquanto mediada por Bandeira, a tradução como reescritura revela o seu caráter transformacional, que envolve vários tipos de transposição de um código para outro. Tomando a tradução dessa perspectiva mais ampla, que aproxima tradução da adaptação, da paráfrase e da paródia, conforme executadas por Manuel Bandeira, produz formas de reescritura fortemente criativas e autorais. 


\title{
4 A Paráfrase
}

Na primeira edição comercial, de 1948, de Poemas traduzidos, um poema de Pierre de Ronsard aparece com o título de "Soneto de Ronsard" e nas edições subsequentes como "Paráfrase de Ronsard". Em ambos os casos, Bandeira responsabiliza-se pelo texto ao publicá-lo em Estrela da vida inteira (1966) e Poesia e prosa (1958), juntamente com outros de sua autoria, em vez de incluí-lo no capítulo dos poemas traduzidos. A mudança do título, de "Soneto de Ronsard" para "Paráfrase de Ronsard", assim como a inclusão entre criações do próprio Bandeira, evidencia sua concepção do processo de tradução poética como uma forma de apropriação e não de imitação.

Essa diferença sutil, e aparentemente insignificante, contribui para a discussão sobre a questão de autoria e de sacralização do original, mesmo tendo Bandeira declarado a sua fonte ao colocar nos títulos o nome de Ronsard, explicitando uma espécie de co-autoria. Heloisa Borges considera que

\begin{abstract}
A intertextualidade que ocorre pela paráfrase não deixa de ser um exercício de desprendimento de várias partes porque se o texto de origem, presente no segundo texto, é o portador de sentido, ele permite, todavia, ser falado em vez de falar, ser apresentado em vez de apresentar, abrindo o jogo íntimo da cumplicidade (BORGES 1992: 38).
\end{abstract}

Nessa cumplicidade revelam-se, concomitantemente, os aspectos dialógico e interpretativo do processo, sendo que o termo paráfrase traz em sua composição o prefixo grego pará- que reforça o aspecto de contiguidade e continuidade. A liberdade assumida na recriação do poema faz transparecer 0 conceito de paráfrase como um processo que não pretende reproduzir, mas produzir algo diferente, sem perder de vista o poema que o motivou. 
Ao confrontarmos o poema de Ronsard e a tradução de Bandeira, verificamos que há correspondência completa na forma do soneto, mas não a equivalência de verso a verso.

\section{Pierre de Ronsard:}

J e vous envoie un bouquet que ma main Vient de trier de ces fleurs épanies Qui ne les eût à ce vêpre cueillies Chutes à terre elles fussent demain.

Cela vous soit un exemple certain Que vos beautés, bien qu'elles soient fleuries, En peu de temps cherront toutes flétries Et comme fleurs périront tout soudain.

Le temps s'en va, le temps s'en va, ma Dame, Las! le temps, non, mais nous nous en allons Et tôt serons étendus sous la lame.

Et les amours desquelles nous parlons, Quand seron morts, ne sera plus mouvelle; Pour ce, aimez-moi cependant qu'êtes belle.

\section{Manuel Bandeira:}

Foi para vós que ontem colhi, senhora, Este ramo de flores que ora envio. Não no houvesse colhido, e o vento e o frio Tê-las-iam crestado antes da aurora.

Meditai nesse exemplo, que se agora Não sei mais do que o vosso outro macio Rosto nem boca de melhor feitio, A tudo a idade altera sem demora.

Senhora, o tempo foge... o tempo foge... Um dia morreremos, e amanhã Já não seremos o que somos hoj e...

Porque é que o vosso coração hesita? 0 tempo foge... A vida é breve e é vã.. . Por isso... amai-me... enquanto sois bonita.

Bandeira ora inverte posições: 01 ㅇv verso de Ronsard corresponde ao $2^{\circ}$ verso de Bandeira; ora insere acréscimos, como os versos da segunda estrófe: Não sei mais do que o vosso outro macio/ Rosto nem boca de melhor feitio; ora substitui versos por outros que se aproximam mais do sentido de um outro poema do próprio Ronsard, "Mignonne allons voir si la rose...", abaixo cotejados:

Tê-las-iam crestado antes da aurora A tudo a idade altera sem demora Por que é que o vosso coração hesita
Ne dure que du matin jusqu'au soir; La veillesse fera tenir votre beauté. Donc si vous me croyez mignonne.

\footnotetext{
${ }^{1}$ A pontuação deste verso é a da edição de Poemas Traduzidos de 1948. Nas edições posteriores (e em Estrela da vida inteira) a pontuação do verso é: "Por isso, amai-me... enquanto sois bonita".
} 
0 resultado é a reprodução de "um sentimento globalizante que percorre a essência da estrutura emotiva do soneto" (BORGES 1992: 42). Em ambos os poemas, Ronsard trabalha temas como a fugacidade da vida, o tempo que destrói a beleza e a ideia de carpem diem. Nessa fusão de elementos dos dois poemas na paráfrase, Bandeira reafirma a poética do poeta francês e evidencia a sua própria capacidade de criador e tradutor.

Essa prática antropofágica de "traduzir" o poeta francês dialoga com 0 programa poético do grupo La Pléiade, do qual Ronsard fazia parte, e que foi de grande importância na renovação da literatura francesa, juntamente com J oachin Du Bellay. Esses poetas comporiam poemas com modelos da lírica grega em língua francesa, pois acreditavam que esta encontrava-se ameaçada pelo latim. Para Mario LaRANJeIRA (1993: 35) trata-se de uma teoria de inutrição, metáfora de devoração crítica, cultural e estética que preconizava "re-trabalhar e re-vivificar os textos em outras línguas-culturas".

Realmente, a prática poética de Bandeira, equilibrando-se entre a tradição e a modernidade, insere-se na proposta do Modernismo de pesquisa estética. Todavia, o próprio Bandeira não se considerava engajado no movimento modernista. Morando no Rio de J aneiro, Bandeira não quis ir a São Paulo na Semana de Arte Moderna, mas em 1922, envia à revista Klaxon (primeira revista do movimento modernista), a pedido de Mário de Andrade, 0 poema "Bonheur lyrique". Conforme relata o poeta: "Foi assim que me vi associado a uma geração que, em verdade, não era minha" e ainda: "nunca atacamos [ele e Ribeiro Couto] publicamente os mestres parnasianos e simbolistas, nunca repudiamos o soneto nem, de um modo geral, os versos metrificados e rimados" (BANDEIRA 1966: 70). Apesar dessa afirmação, Bandeira não se furta de satirizar a poesia dos Românticos e Parnasianos, nas suas "traduções para o moderno". 


\title{
5 A "tradução para o moderno"
}

\begin{abstract}
Duas "traduções para o moderno", como Bandeira chama essas recriações, foram publicadas, numa mesma tiragem, na seção "Mês Modernista" do jornal A Noite, em 1925. Tratava-se de uma galhofa por não levar muito a sério a incumbência de participar no movimento literário que despontava: "o que fiz foi me divertir ganhando cinquenta mil-réis por semana, o primeiro dinheiro que me rendeu a literatura" (idem: 92). Eram duas versões: uma de um soneto de Bocage e a outra de um poema de Castro Alves, abaixo confrontadas com o original:
\end{abstract}

\section{Bocage:}

Se é doce no recente, ameno Estio Ver toucar-se a manhã de etéreas flores, $\mathrm{E}$, lambendo as areias e os verdores, Mole e queixoso deslizar-se o rio;

Se é doce o inocente desafio Ouvirem-se os voláteis amadores, Seus versos modulando e seus ardores Dentre os aromas de pomar sombrio;

Se é doce mares, céus ver anilados Pela quadra gentil, de Amor querida, Que esperta os corações, floreia os prados,

Mais doce é ver-te de meus ais vencida, Dar-me teus brandos olhos desmaiados Morte, morte de amor, melhor que a vida. 
Prado, Célia Luiza Andrade - Tradução, Paródia e paráfrase: as reescrituras poéticas de Manuel Bandeira

\section{Bandeira:}

Doçura de, no estio recente,

Ver a manhã toucar-se de flôres,

E o rio

mole

queixoso

Deslizar, lambendo areias e verduras:

Doçura de ouvir as aves

Em desafio de amôres

cantos

risadas

Na ramagem do pomar sombrio

Nessa tradução intralingual, usando um termo de Jakobson, observa-se a manutenção do tom lírico do poema de Bocage. Entretanto, é na espacialização dos versos que se acha a ironia da "tradução para o moderno", conforme explica BANDEIRA (1966: 92): "Como se vê, eu estava assinalando maliciosamente certas maneiras de dizer, certas disposições tipográficas que já se tinham tornado clichês modernistas". Assim, a paráfrase do tema de Bocage seria, também, uma paródia do aspecto formal da poesia modernista.

A outra "tradução para o moderno" era do "Adeus de Teresa":

\section{Castro Alves:}

A VEZ PRIMEIRA que vi Teresa,

Como as plantas que arrasta a correnteza,

A valsa nos levou nos giros seus...

E amamos juntos... E depois na sala

"Adeus" eu Ihe disse a tremer co'a fala...

E ela, corando, murmurou-me: "adeus".

Uma noite... entreabriu-se um reposteiro...

E da alcova saía um cavaleiro

Inda beijando uma mulher sem véus...

Era eu... Era a pálida Teresa!

"Adeus" Ihe disse conservando-a presa...

E ela entre beij os murmurou-me: "adeus!"

Passaram tempos... séculos de delírio

Prazeres divinais... gozos do Empíreo... 
...Mas um dia volvi aos lares meus.

Partindo eu disse - "Voltarei! descansa!..."

Ela, chorando mais que uma criança,

E ela em soluços murmurou-me: "adeus!"

Quando voltei... era o palácio em festa!...

E a voz d'Ela e de um homem lá na orquestra

Preenchiam de amor o azul dos céus.

Entrei!... Ela me olhou branca... surpresa!

Foi a última vez que vi Teresa!...

E ela arquejando murmurou-me: "adeus!"

\section{Bandeira:}

A primeira vez que vi Teresa

Achei que ela tinha pernas estúpidas

Achei também que a cara parecia uma perna

Quando vi Teresa de novo

Achei que os olhos eram muito mais velhos que o resto do corpo

(os ol hos nasceram e ficaram dez anos esperando que o resto do corpo nascesse)

Da terceira vez não vi mais nada

Os céus se misturaram com a terra

E o espírito de Deus voltou a se mover sobre a face das águas

Diferentemente da "tradução para o moderno" de Bocage, na de Castro Alves observa-se a ironia, acentuada pela utilização de linguagem coloquial e da bíblica nos dois últimos versos. Bandeira não só parodia a forma como também o tema de "Adeus a Teresa". Sobre esse poema diz BandeIRA (1966: 94): "Num comentário, de humor muito sofisticado, dava o meu poema "Teresa" como tradução tão afastada do original, que a espíritos menos avisados pareceria criação".

Teresa é um nome recorrente na poesia de Bandeira evidenciando a intertextualidade com Castro Alves e a intratextualidade com seus próprios poemas, como "Madrigal engraçadinho", e com o poema a seguir, parodiado de J oaquim Manuel de Macedo. Esta "tradução para o moderno" foi publicada no mesmo jornal, A Noite, na semana seguinte, com a intenção somente de 
brincar com linguagem cafajeste e foi apresentada como uma tradução pra caçanje:

\section{Macedo:}

Mulher, irmã, escuta-me: não ames.

Quando a teus pés um homem terno e curvo

J urar amor, chorar pranto de sangue,

Não creias, não mul her: ele te engana!

As lágrimas são galas de mentira

E o juramento manto da perfídia.

\section{Bandeira:}

Teresa, se algum suj eito bancar o sentimental em cima de você

E te jurar uma paixão do tamanho de um bonde

Se ele chorar

Se ele se rasgar todo

Não acredita não Teresa

Se ele se aj oel har

É lágrima de cine

É tapeação

Mentira

CAI FORA.

Assim como a paráfrase, a paródia também se define pela intertextualidade, contudo, diferentemente da paráfrase, a paródia é marcada pelo deslocamento de uma motivação cômica ou irônica e pelo antagonismo de vozes que engendra uma oposição crítica do recriador, em relação ao original. A "descontinuidade" na paródia atrai os movimentos literários radicais do início do séc. XX como o Futurismo e o Dadaísmo. SANT'ANNA (1985: 7) anota que "a frequência com que aparecem textos parodísticos testemunha que a arte contemporânea se compraz num exercício de linguagem onde a linguagem se dobra sobre si mesma num jogo de espelhos".

A ironia contida na paródia é apontada por Bosl (2002: 351) em poemas de Bandeira e Mário de Andrade como característica de "concepção modernista de poesia". O teórico, todavia, critica a "inconsistência ideológica" dos grupos modernistas e adverte que o "culto a blague" é uma 
das manifestações que impede "que os modernistas repensem com objetividade o problema de sua inserção na práxis brasileira" (idem: 343).

Em "Sapos", poema declamado na semana de 22, Bandeira parodia 0 verso de Bilac, Imito o ourives quando escrevo, "mais contra certos ridículos do pós-parnasianismo" (1966: 59):

\author{
Clame a saparia \\ Em críticas céticas: \\ Não há mais poesia, \\ Mas há artes poéticas... \\ [...] \\ Brada em um assomo \\ O sapo-tanoeiro: \\ - "A grande arte é como \\ Lavor de joalheiro
}

A irreverência de Bandeira é uma investida contra os modelos poéticos rígidos e vocabulário erudito e também, mais uma vez, uma sátira aos modernistas. Essas brincadeiras não foram totalmente inconsequentes e na avaliação de Bandeira estigmatizaram a poesia moderna:

Por essas e outras brincadeiras agora estamos pagando caro, porque 0 "espírito de piada", o "poema-piada" são tidos hoje por característica precípua do modernismo, como se toda a obra de Murilo, de Mário de Andrade, De Carlos Drummond de Andrade e outros, eu inclusive, não passasse de um chorrilho de piadas (ibid.).

Com efeito, PAES (1990: 59) considera o poema-piada a "pedra de toque do modernismo irreverente e iconoclasta de 22"; Candido é menos taxativo, mas também atribui à "valorização do prosaico e o bom humor" como elementos purificadores da "atmosfera carregada pelos acadêmicos":

O humorismo não era considerado elemento aceitável pela poesia "séria" tradicional. Uma das grandes conquistas dos modernos foi introduzi-lo, sob forma de ironia ou de paradoxo, utilizando-o como instrumento de análise moral, aprofundamento de emoções e senso da complexidade do homem e do mundo (CANDIDO 2006: 24). 
Para Bandeira poesia não implica temas nobres e elevados: "a poesia existe tanto nos amores como nos chinelos" (BANDEIRA 1966: 11). Haroldo de CAMPOS (2004: 115) descreve este tipo de poesia como sendo de linha coloquial-irônica cuja simplicidade emocional, quase uma trivialidade, é sustentada pela habilidade do poeta, que partindo do lugar comum revela um ângulo novo e produz uma informação estética nova, ou seja, partindo do lugar comum para o lugar incomum.

\section{6 À maneira de}

A poética de Bandeira se caracteriza pela multiplicidade de técnicas e mistura de estilos e se equilibra entre tradição e modernidade. Bandeira refaz a tradição compondo sonetos, madrigais, baladas e outras formas clássicas. Nesse exercício de "imitação formal", escreve poemas "à maneira de...", sendo um deles com estilo semelhante ao de e.e.cummings.

Cummings ficou conhecido pela maneira gráfico-espacial com que trabalha sua poética, que incluem a utilização não ortodoxa tanto das letras maiúsculas quanto da pontuação, com as quais, inesperadamente, de forma aparentemente imotivada, é capaz de interromper uma frase, ou mesmo palavras isoladamente. Muitos de seus poemas possuem, também, uma distribuição não convencional dos versos na página, aparentando pouco ou nenhum sentido. Assim, a poesia de e.e. cummings dialoga com as artes visuais apagando as fronteiras entre texto e imagem e aproximando diferentes manifestações artísticas. São poemas para serem vistos e não somente ouvidos, exigindo do espectador/leitor um exercício de decodificação para que o sentido vá se formando sutil e gradualmente na mente.

O poema de Bandeira, inspirado em e.e. cummings, é parte do "diálogo poético" que Bandeira mantém com Elisabeth Bishop decorrente da troca de livros e de cartas-poemas. Em agradecimento ao livro enviado por Bandeira, 
Bishop oferece um pote de geleia e um outro livro, acompanhados dos versos intitulados To Manuel Bandeira with a present. Especula-se que o livro presenteado por Bishop seja XAIPE, a julgar, sobretudo, pela última linha "Xaire Elisabeth"2 do poema à maneira de e.e.cummings, que Bandeira compõe em agradecimento:

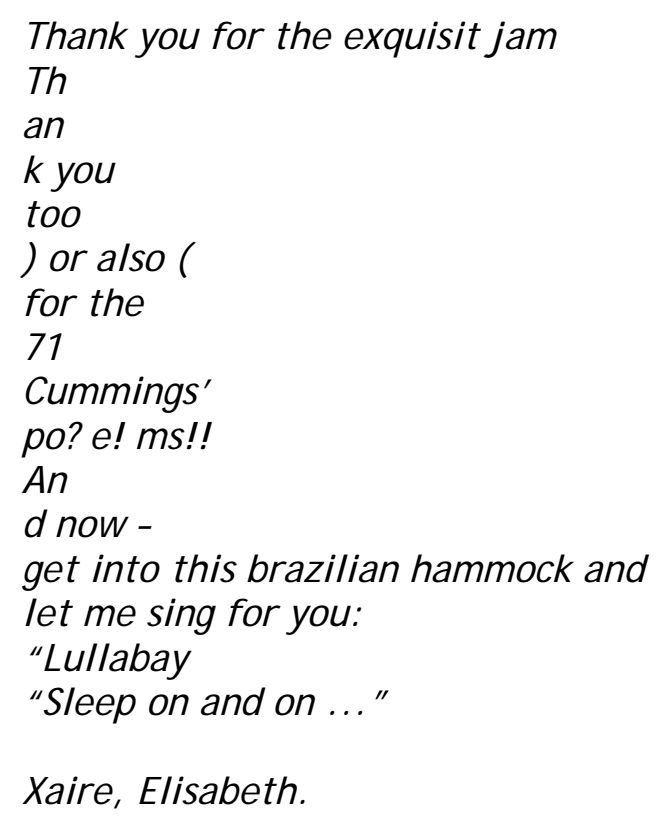

Nessa "galhofa poética", Bandeira se apropria da forma de e.e. cummings para agradecer uma obra de cummings (XAIPE), na língua de sua interlocutora, e ainda dos versos de Bishop, Lullabay / Sleep on and on, para niná-la na rede brasileira (brazilian hammock). Esses versos de Bishop são do poema "Songs for a colored singer" do qual Bandeira traduz a terceira parte e inclui na edição de Poemas traduzidos de 1956, sob o título de "Acalanto", como se fosse um poema autônomo.

Apesar de conter características da paráfrase, esse poema em agradecimento não parte de um texto fonte, condição si ne qua non da transposição textual. Para considerá-lo paródia seria necessário entender que Bandeira estivesse criticando a maneira de e.e. cummings fazer poesia.

\footnotetext{
${ }^{2}$ Cf. Flora SÜSSEKIND. A geléia e o engenho: em torno da carta-poema de Elizabeth Bishop a Manuel Bandeira.
} 
Consequentemente, a classificação dessa obra torna-se ambígua, pois pode tanto ser considerado um tributo como uma sátira a e.e. cummings.

SANT'ANNA (1985: 61) teoriza a respeito da diferença entre paródia e paráfrase, identificando ambas recriações como uma ato de apropriação, havendo "um deslocamento da propriedade do texto, a eliminação dos donos da escrita, a possibilidade de cada criador manipular o real do texto segundo suas inclinações críticas".

\section{Considerações Finais}

As traduções de Bandeira, por vezes, se fundem com a autoria e conforme atesta MiLton (1993: 170), "várias de suas traduções, tais como a atualização do soneto de Castro Alves, Adeus a Teresa, e dos de Elizabeth Barrett Browning, são geralmente reconhecidas como de maior interesse do que os originais". Para WANDERLEY (1988: 62),

\footnotetext{
Ler aquele livro (Poemas traduzidos) era como ler o próprio Bandeira, assim como ainda hoje e para todo o mundo ler sua Paráfrase de Ronsard é ler Bandeira [...]. A tradução (Ronsard) adquiriu tamanho grau de existência própria que o poema-fonte fica mais e mais distante da lembrança.
}

PAES (1990: 55) considera "a figura de tradutor, menos importante que a de poeta [...] mas, por ser complementar dela, igualmente digna de interesse". Para outros, tradutor e poeta se confundem; BACIú (1966: 88) declara que na poesia Bandeira é, antes de tudo, um tradutor nato, e é por isso que só se sente capaz de traduzir aqueles poemas cujo autor gostaria de haver sido; e BosI (2002: 361) confirma que Bandeira era um "homem de métier, capaz de compor em todos os ritmos e de traduzir com igual maestria Shakespeare e Holderlin, Rilke e García Lorca". 
O reconhecimento da relação entre tradução e os exercícios "recriativos" de Bandeira pode ser passível de contestação: "A noção de transgressão como fator constitutivo da prática tradutória não significa que qualquer forma de produção textual ou interpretação seja aceita como tradução" (AMORIM 2005: 39). A grande questão reside na impossibilidade de se estabelecerem limites e de se elaborarem definições "unívocas":

Os limites aqui são marcados pelos seus complexos redimensionamentos em termos de discurso nos quais ambos os conceitos de tradução e adaptação, e os respectivos corpora textual a que se ligam acham-se inscritos (AMORIM 2003: 195).

\section{Referências bibliográficas}

AMORIM, L. M. Translation and adaptation: differences, intercrossings and conflicts in Ana Maria Machado's translation of Alice in Wonderland by Lewis Carroll. In: MILTON, J.; TORRES, M.-H. C. Cadernos de tradução (Orgs.). no 11. Pós-graduação em estudos da tradução - PGET. Universidade Federal de Santa Catarina, 2003.

Tradução e adaptação: Encruzilhadas em Alice no País das Maravilhas, de Lewis Carrol, e Kim, de Rudyard Kipling. São Paulo: UNESP. 2005.

ANDRADE, M. Cartas a Manuel Bandeira. Rio de J aneiro: Tecnoprint, 1957.

; BANDEIRA, M. Itinerários: cartas a Alphonsus de Guimarães Filho. São Paulo: Duas Cidades, 1974.

BACIÚ, S. Manuel Bandeira de corpo inteiro. Rio de Janeiro: José Olympio, 1966.

BAndeIRA, M. Poesia e prosa. 1 ed. vol I. Rio de J aneiro: J osé Aguilar, 1958 a. . Poesia e prosa. 1 ed. vol II. Rio de J aneiro: J osé Aguilar, 1958 b. - Itinerário de Pasárgada. 3 ed. São Paulo: Editora do Autor, 1966. . Andorinha, andorinha. São Paulo: Círculo do Livro, 1978.

Benj AmIN, W. A obra de arte na época da sua reprodutibilidade técnica. In: Adorno et al. Teoria de cultura de massa. Trad. Carlos Nelson Coutinho. São Paulo: Paz e Terra, 2000. 
Prado, Célia Luiza Andrade - Tradução, Paródia e paráfrase: as reescrituras poéticas de Manuel Bandeira

. The task of the translator. In: SCHULTE, Rainer; BIGUENET, John. Theories of translation. Chicago \& London: Chicago University Press, 1992.

BISHOP, E.: BRASIL, E (Orgs.). An anthology of 20th century Brazilian poetry. Middleton, Connecticut: Wesley University Press, 1972.

BoRgES, H. H. de C. Bandeira está para Ronsard... Signótica. Revista do Programa de Pós-Gradução em Letras e Linguística. Universidade Federal de Goiás. n. 4. jan./ dez. 1992: 37-46.

CAmpos, H. de. A arte no horizonte do provável. 4 ed. São Paulo: Perspectiva, 1977.

. Metalinguagem e outras metas. 4 ed. São Paulo: Perspectiva, 2004.

. Paul Valéry e a poética da tradução. Folha de São Paulo. Folhetim. 27 de jan, 1985. São Paulo.

Coelho, E. dos S. C. Arqueologia da composição: Manuel Bandeira. Tese de doutoramento. Programa de pós-graduação em Letras Vernáculas. Universidade Federal do Rio de J aneiro. 2009.

Du Bellay, J. Défense et illustration de la langue française. Disponível em: বttp:/ / www.tlfq.ulaval.ca/ axl/ francophonie/ Du_Bellay. htm>. (06/01/2010).

Garbuglio, J. C. Roteiro de leitura: poesia de Manuel Bandeira. São Paulo: Ática, 1998.

LARANJ eIRA, M. Poética da tradução. São Paulo: Edusp, 1993.

LEFEVERE, A. Translation, rewriting and the manipulation of literary fame. London \& New York: Routledge, 1992a.

- Mother Courage's cucumbers: text, system and refraction in a theory of literature. In: VENUTI, L. (Org.). The translation studies reader. London \& New York: Routledge, 2003.

MILton, J. O poder da tradução. São Paulo: Ars Poética, 1993.

PAES, J. P. Tradução: ponte necessária. São Paulo: Ática, 1990.

RenAULT, A. Notas à margem de algumas traduções de Manuel Bandeira. In: Homenagem a Manuel Bandeira. Brasília: Senado Federal, 1986.

SANTANA, V. D. A dicotomia tradutor/ autor na leitura de "A tarefa do tradutor", de Benjamin, por Derrida. Trabalhos de linguistica aplicada. vol. 47 n. 1 Campinas, J an./ J une 2008: 251-262.

Sant 'anna, A. R. de. Paródia, paráfrase \& cia. 4 ed. Ática: São Paulo, 1991.

SüSSEKIND, Flora. "A geléia e o engenho: em torno de uma carta-poema de Elizabeth Bishop a Manuel Bandeira". Fundação Casa Rui Barbosa. Rio de Janeiro. Disponível em: «www.casaruibarbosa.gov.br $>$. (20/01/2010). 
Prado, Célia Luiza Andrade - Tradução, Paródia e paráfrase: as reescrituras poéticas de Manuel Bandeira

VenUtI, L. Escândalos da tradução. Trad. Laureano Pelegrino et al. Bauru: EUSC, 2002.

WANDERLEY, J. A tradução do poema entre poetas do modernismo: Bandeira, Guilherme de Almeida, Agar Renault. 1988. Tese de doutoramento em Letras. Pontifícia Universidade Católica do Rio de J aneiro. 